\title{
INVESTIGATE VEHICLE DESIGN PARAMETERS EFFECT ON DYNAMIC VEHICLE STABILITY
}

\author{
Mina. M. Ibrahim*, K. A. Abd El-Gwwad, M. M. M. Salem, and M. Mourad \\ Automotive and Tractors Eng. Dept., Faculty of Engineering, Minia University, El-Minia Egypt, 6111 \\ E-mail: *mina.magdy@mu.edu.eg
}

\begin{abstract}
In this paper, a two degree of freedom linear vehicle model is proposed to investigate dynamic vehicle stability under varies vehicle maneuvers. The simulation is developed using MATLAB/Simulink application program to predict the vehicle dynamic stability under different maneuvers. To investigate vehicle stability, the Steering wheel angle is chosen to be the primary model input for the analysis procedures. The developed model is validated via Step steer input. Moreover, a new typical steer wheel angle is developed to examine highway predicted vehicle output within its maneuver. The vehicle dynamic outputs, namely, yaw rate and lateral acceleration are adopted for all the investigated maneuvers. It is found that the vehicle design parameters such as changing the vehicle center of gravity (CG) position, vehicle mass, tire cornering stiffness and vehicle speed have a significant influence on the vehicle dynamic stability. Change in vehicle center of gravity position is the most parameter has an influence in vehicle stability dynamics. $10 \%$ forward and reward in the C.G position change in under steering gradient, it changes steering in vehicle model from under steering type to over steering type, on the other hand, vehicle mass change $\pm 10 \%$ change in vehicle mass has the latest influence in vehicle stability dynamic. Others have a different rate effect on vehicle dynamic stability.
\end{abstract}

Keywords: Yaw rate, vehicle stability dynamics, parameters.

\section{INTRODUCTION}

In this research, vehicle stability is investigated during its maneuvering versus steering excitations (step input and typical steer angle) which are used as the major input for the proposed vehicle model. In this manner, a complete parametrical analysis is needed regarding a complete understanding of the vehicle stability characteristics and sensitivity. Furthermore, a conflict analysis can illustrate the trade-off between the vehicle stability indices during different conditions and with respect to the design parameters. Several researchers had studied vehicle stability either theoretically via the simulation software like the MATLAB/Simulink or experimentally including both the laboratory and on-field experiments[1].Dynamic stability of vehicles depends on varies maneuver conditions such as traction, braking, and cornering. knowingly, both the yaw rate and lateral acceleration are usually used to represent and investigate the theoretical handling performance for vehicle models which defined the stability region under varies maneuver features [2].Lateral stability and vehicle handling performance have a significant notice in most automotive research recently. Many sever accident was resulted due to vehicle in stability during maneuvering[3]. In the vehicular stability academic literature, several researchers have analyzed the vehicle stability and handling trends considering varies steering inputs including the step steer, triangle pulse, right angle, triangle pulse, rectangular pulse, sinusoidal pulse, and sinusoidal sweep [4].The steering system is the interface between the vehicle and road. In the rubberwheeled vehicle, steering systems are represented by a mechanical linkage between the driver, vehicle and the front wheel[5]. Steering input is an indicationof the type of road perturbation and defines the torque on both the road and wheel, and it varies depending on road condition[6]. Vehicle design parameters including 
geometrical and suspension parameters have a remarked effect on vehicle stability and handling during the maneuvering and real driving. Theladen and un laden conditions during vehicle maneuvering can highly affectvehicl estability[7, 8].Center of gravity (C.G) is also a critical parameter which affects vehiclestability eventually. The change is the C.G position can also affect the vehicular stability and handling based on the vehicle body mass distribution since the change in vehicle mass distribution on both the front and rear wheels have a significant effect on vehicle handling and stability[9, 10].Traveling on roads, vehicle speeds and cornering radius presented remarked effect on vehicle stability including the yaw rate and lateral acceleration which can be estimated during the simulations under varies speed and steering maneuver [11].

Based on the aforementioned key observations from the previously published literature, this paper presented complete parametrical and conflict analyses including the geometrical and vehicle design parameters were conducted. During the simulations, a 2-DOFs bicycle-vehicle model was implemented and verified and thereafter two steering modes were used to examine the sensitivity of vehicular stability and handling performances. In this manner, both the yaw rate and vehicle lateral acceleration were mainly considered as the vehicle stability indices.

\section{SYSTEM MODELING}

\subsection{Model assumptions}

Figure 1 presents a 2-DOFs linear vehicle model to analyze the dynamic stability under varies maneuvers. The equations of motion for the proposed model were generally derived based on Newton's law of motion. The modeling is carried out utilizing the following assumptions [12]:

1. A level flat road surface, so that's no drag road or gradient.

2. A rigid vehicle body (no suspension system).

3. The steering applied input was performed at the steering wheel through a fixed gear ratio.

4. Neglect aerodynamic force compared with tire forces.

5. The vehicle has a small perturbation within vehicle maneuver, so it leads to road wheel steer angle and the linear equation of motion.

6. The forward speed is constant.

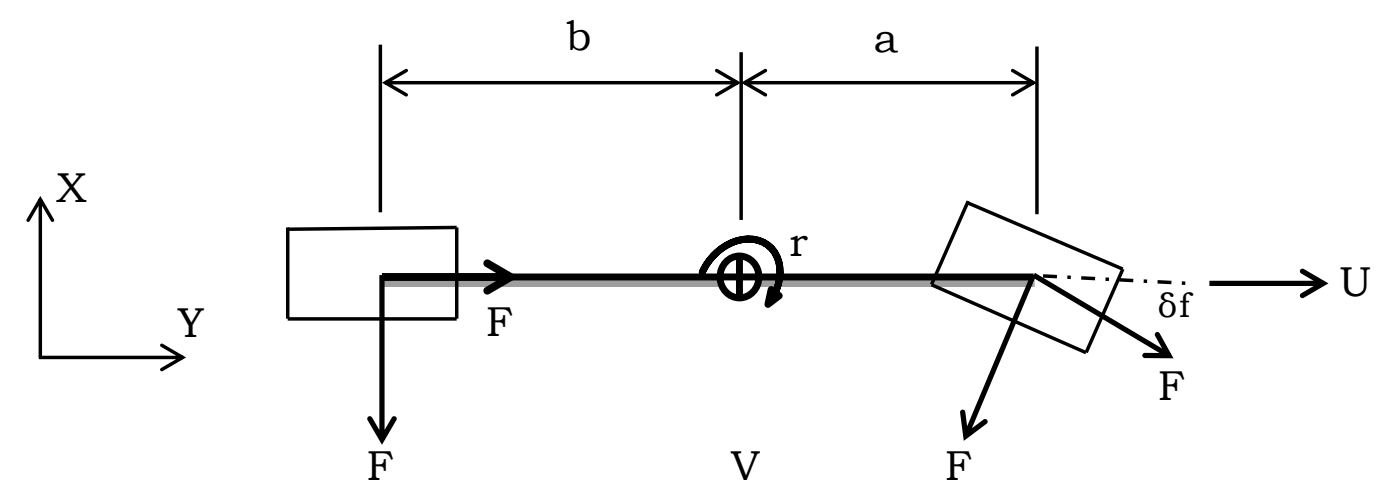

Fig. 1.Linear vehicle model[12].

\subsection{Equation of motion}

In the handling model, external forces are presented by a tire which depends on velocities. Velocities and accelerations reflected driver sees and feels for vehicle behaviors. These velocities and acceleration can be investigated by a coordinate system; this system is fixed, and it moved with vehicle[12].
Applying Newton law for motion on the modelgeneratesthe equationof the longitudinal force:

$m(\dot{u}-v r)=f_{x f}+f_{x r}$

Lateral force:

$m(\dot{v}+u r)=f_{y f}+f_{y r}$

Yaw moment:

$I \dot{r}=a f_{y f}-b f_{y r}$ 
This case study assumes that the forward speed U constant, so the equation (1) disappeared, so the equations are:

$m(\dot{v}+u r)=f_{y f}+f_{y r}$

$I \dot{r}=a f_{y f}-b f_{y r}$

Where $u$ is forward speed, and it was in $\mathrm{x}$-direction, $\mathrm{v}$ is the lateral velocity, and it was in $y$-direction, $r$ is the angular velocity (yaw rate), and it was in z-direction, $f_{y f}$ and $f_{y r}$ the lateral force on front and rear wheel respectively, $m$ was defined as vehicle mass and I was defined as yaw inertia, a and b was defined as the distance between the center line of front and rear wheel to the point of the center of gravity of vehicle respectively.

Then we investigate tire forces which it in terms of the system:

$f_{y f}=-C_{f} \alpha_{f}$

$f_{y r}=-C_{r} \alpha_{r}$

Where $\mathrm{C}_{\mathrm{f}}$ and $\mathrm{Cr}$ was defined as cornering stiffness for front and rear wheel respectively, $\alpha_{f}$ and $\alpha_{r}$ was defined as slip angle for front and rear wheel respectively.

Slip angle can also be defined as:

$\alpha_{f}=\frac{v+a r}{U}-\delta_{f}$

$\alpha_{r}=\frac{v-b r}{U}$

From Eqs. (8) and (9) equation of motion will be:

$$
\begin{aligned}
& m(\dot{v}+U r)=-\frac{\left(C_{f}+C_{r}\right)}{U} v-\frac{\left(a C_{f}-b c_{r}\right)}{U} r+ \\
& C_{f} \delta_{f} \\
& I \dot{r}=-\frac{\left(a C_{f}-b C_{r}\right)}{U} v-\frac{\left(a^{2} C_{f}+b^{2} C_{r}\right)}{U} r+a C_{f} \delta_{f}
\end{aligned}
$$

Applying the state space theory on Eqs. (10) and (11) to give input in a term and output in the other term:

$$
\begin{aligned}
& {\left[\begin{array}{ll}
m & 0 \\
0 & I
\end{array}\right]\left[\begin{array}{l}
\dot{v} \\
\dot{r}
\end{array}\right]+} \\
& {\left[\begin{array}{cc}
\frac{\left(C_{f}+C_{r}\right)}{U} & m U+\frac{\left(a C_{f}-b C_{r}\right)}{U} \\
\frac{\left(a C_{f}-b C_{r}\right)}{U} & \frac{\left(a^{2} C_{f}+b^{2} C_{r}\right)}{U}
\end{array}\right]\left[\begin{array}{l}
v \\
r
\end{array}\right]=} \\
& {\left[\begin{array}{c}
C_{f} \\
a C_{f}
\end{array}\right]\left[\delta_{f}\right]}
\end{aligned}
$$

We can write it in the form:

$P \dot{x}+Q x=R u$

In which $\mathrm{x}$ is the state variable vector and $\mathrm{u}$ being the input vector:

$x=\left[\begin{array}{l}v \\ r\end{array}\right] u=\left[\delta_{f}\right]$

\subsection{MATLAB/Simulink model}

Figure 2showsa bicycle-vehicle model that was built via the MATLAB/Simulink program by using its toolbox. This model presented input signal for it, the input signal in the matrix equation expresses steering angle and output signals were yaw rate and lateral acceleration that shown in the equations of motion. During the simulation trials, the input signal was the step steer input that used to verify the model. By using Simulink toolbox content, we can express this equation by some blocks that define this equation. Vehicle parameters are defined by constant blocks, and its values were defined in MATLAB m-file.

The output later a acceleration was defined as:

$$
A_{y}=\dot{v}+u r
$$




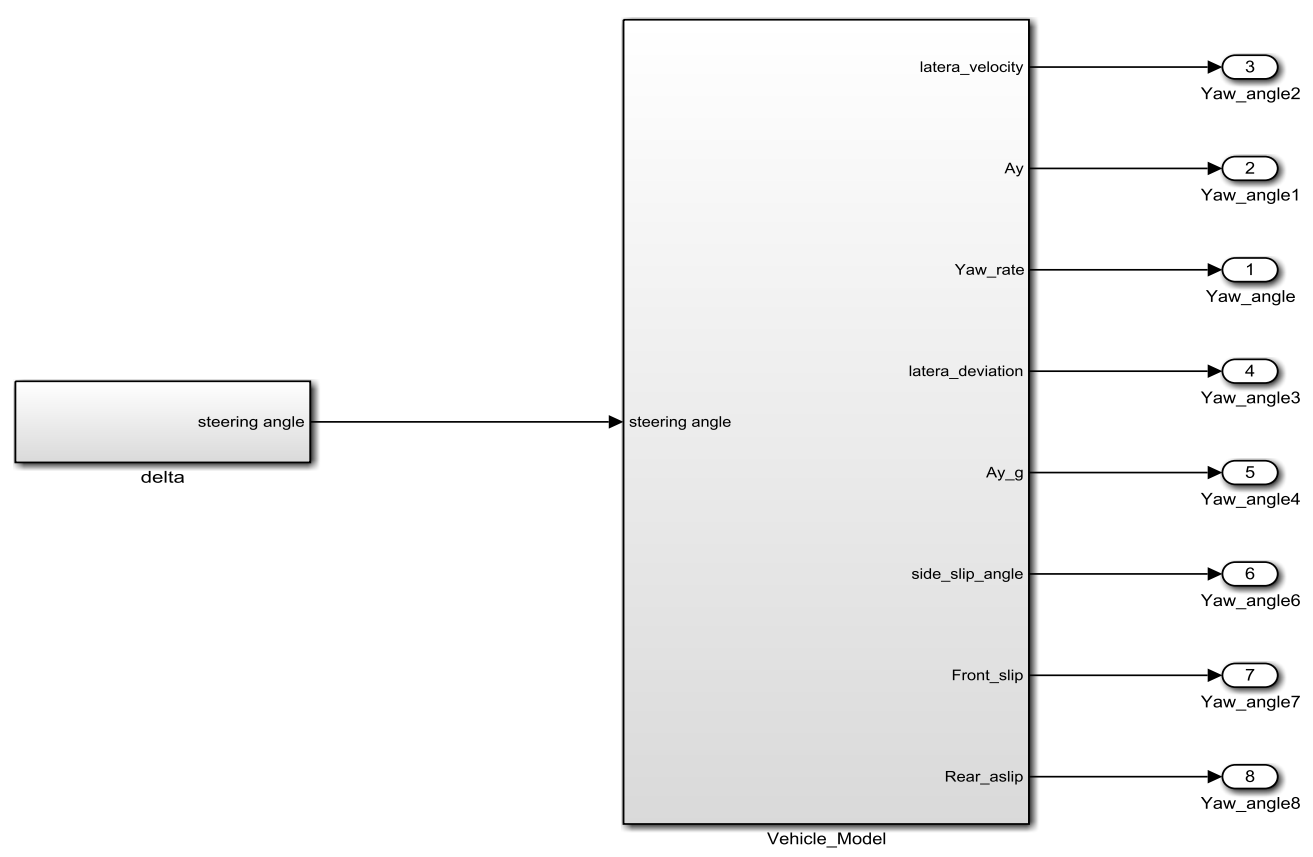

Fig. 2. Linear Vehicle model by MATLAB/Simulink.

\section{SIMULATION ASSESSMENT}

In this section, the analysis for the model was presented by the simulation process which defined and estimated by a sequence which investigates the results. The MATLAB/Simulink was used to define the model, and then the simulation was carried out by the fourth order Runge-Kutta numerical solver. The simulation was at 10 second this time was defined as the simulation time. Vehicle model data and variables are defined in Table1 according to reference[12]. Yaw rate response was presented under step steer input was adjusted to give a steady state lateral acceleration $0.3 \mathrm{~g}$. and at velocity $50 \mathrm{~m} / \mathrm{s}$. Figures below show steering input as a step steer input and the output yaw rate and lateral acceleration during simulation for vehicle parameters values that presented. Figures 3, 4 and 5 describe model input and vehicle handling output respectively

Table 1. vehicle parameter values [12].

\begin{tabular}{|l|l|l|l|}
\hline Parameters & Symbol & Units & Value \\
\hline Mass & $\mathrm{M}$ & $\mathrm{Kg}$ & 2045 \\
\hline Yaw inertia & $\mathrm{I}$ & $\mathrm{Kg} . \mathrm{m}^{2}$ & 5428 \\
\hline Distance from C.G to front axle & $\mathrm{A}$ & $\mathrm{m}$ & 1.488 \\
\hline Distance from C.G to rear axle & $\mathrm{B}$ & $\mathrm{m}$ & 1.712 \\
\hline Front axle cornering stiffness & $\mathrm{C}_{\mathrm{f}}$ & $\mathrm{KN} / \mathrm{rad}$ & 77850 \\
\hline Rear axle cornering stiffness & $\mathrm{C}_{\mathrm{r}}$ & $\mathrm{KN} / \mathrm{rad}$ & 76510 \\
\hline Understeer gradient & $\mathrm{K}$ & $\mathrm{deg} / \mathrm{g}$ & .913 \\
\hline
\end{tabular}



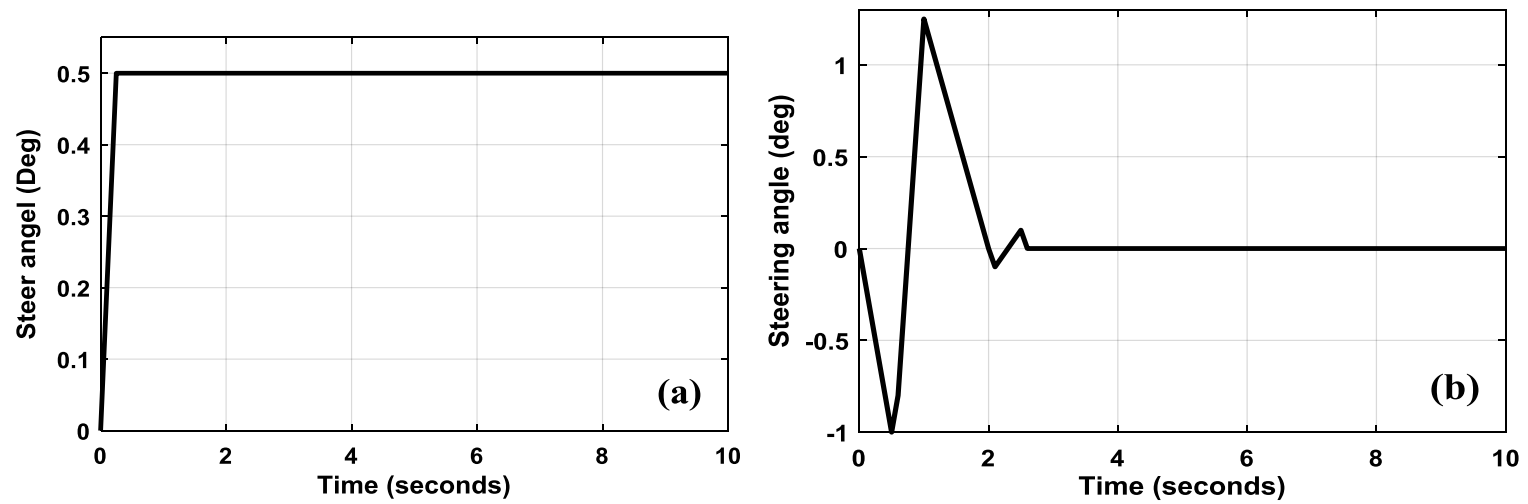

Fig. 3. (a) Step steer wheel angle, (b) typical steering wheel angle.
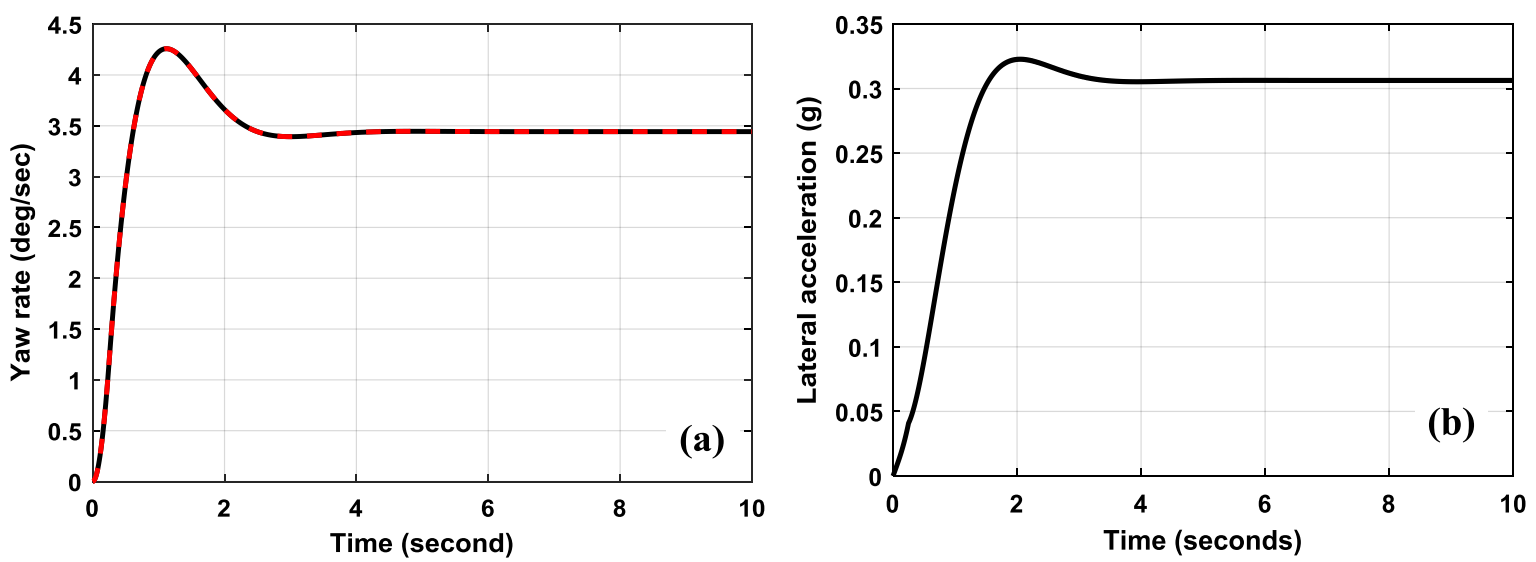

Fig. 4. Output verification comparison with the standard model by Crolla; (a) yaw rate stability for step steer angle at speed of $50 \mathrm{~m} / \mathrm{s}$, (b) lateral acceleration for step steer angle at $50 \mathrm{~m} / \mathrm{s}$ speed.

\section{RESULTS AND DISCUSSION}

Vehicle parameters have an effect in dynamic vehicle stability during vehicle maneuvers, any changes in parameters values effect on vehicle performance during the maneuver. In this section, it will discuss the performance of the vehicle under a typical input that was published in reference[13]. Typical input was adjusted to give a steady state lateral acceleration $0.3 \mathrm{~g}$, typical input carried out to investigate the performance of a vehicle model under this

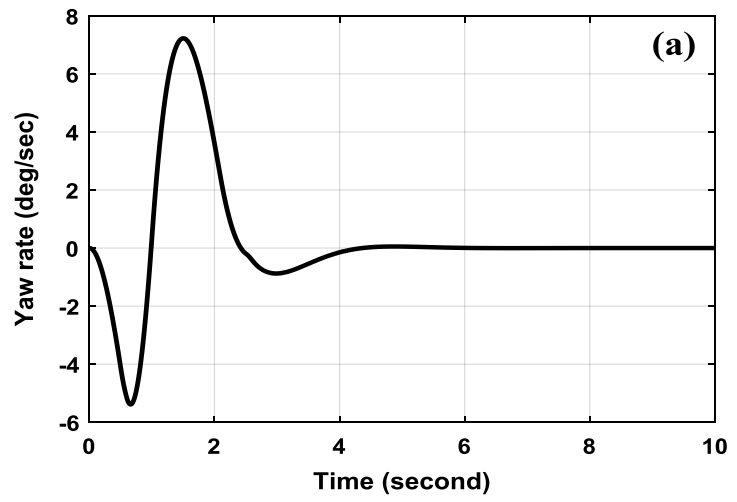

maneuver as a simulation for an actual condition maneuver. Figure $3 b$ shows the wheel steering angle input for typical steering angle, while the lateral acceleration is shown in Fig. 5b and it goes to zeros as a steady state condition like steering angle. The yaw rate stability is presented in Fig. 5ain which its trend is peaked and then go to zeros respecting to the steady state condition.

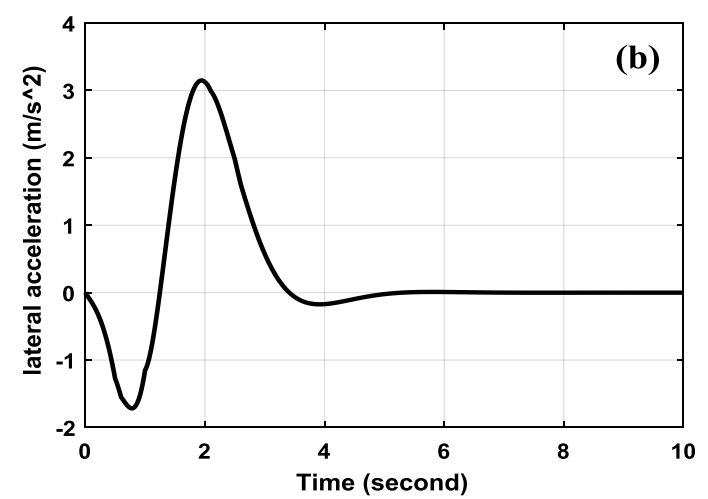

Fig. 5.Handling performance output for typical wheel steer angle at vehicle speed $50 \mathrm{~m} / \mathrm{s}$; (a) yaw rate, (b) lateral acceleration. 
Table 2 presents vehicle parameter design value changes which effect of vehicle dynamic performance during its influence. The cornering stiffness, vehicle weight, vehicle speed and vehicle center of gravity position are the parameters which influence vehicle performance during its maneuvers. Figures6a, 6b, 7a,7b, 8a, 8b, 9a, and 9bshow the influence of front and rear cornering stiffness respectively on yaw rate and lateral Acceleration.

Table 2. vehicle parameters change.

\begin{tabular}{|c|c|}
\hline Vehicle parameter & Percentage of change \% \\
\hline Front cornering stiffness & $\pm 10 \%$ \\
\hline Rear cornering stiffness & $\pm 10 \%$ \\
\hline Gross vehicle weight & $\pm 10 \%$ \\
\hline C.G position & $10 \%$ forward and reward \\
\hline
\end{tabular}
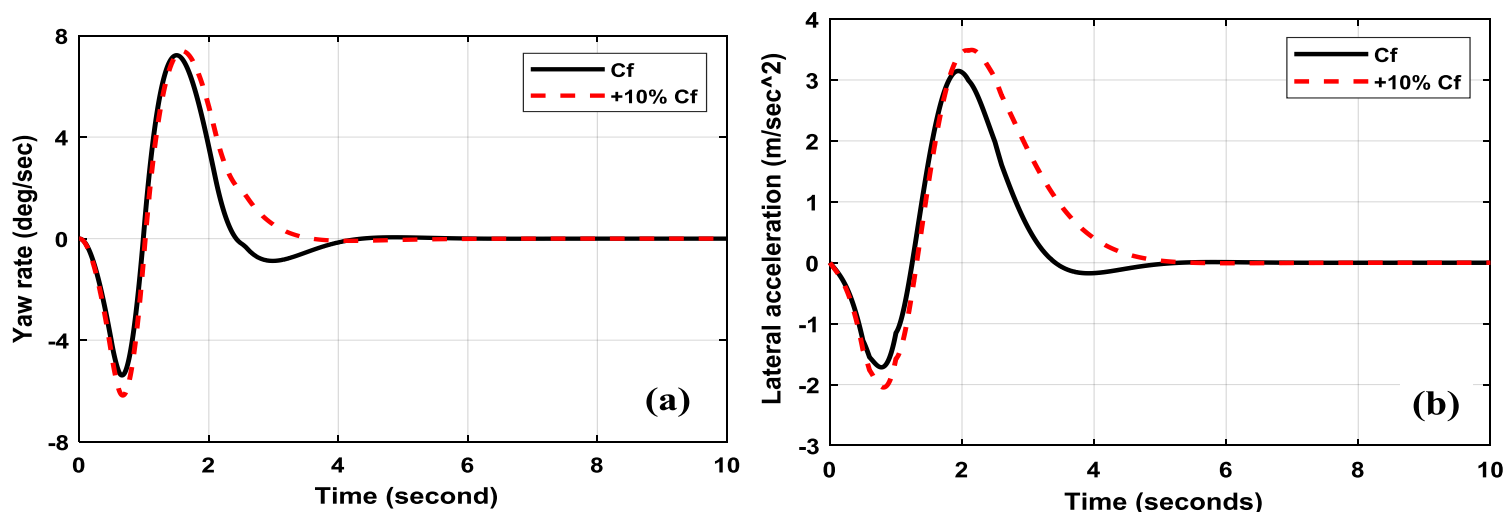

Fig. 6. Handling performance at $+10 \%$ front cornering stiffness variation; (a) yaw rate, (b) lateral acceleration.
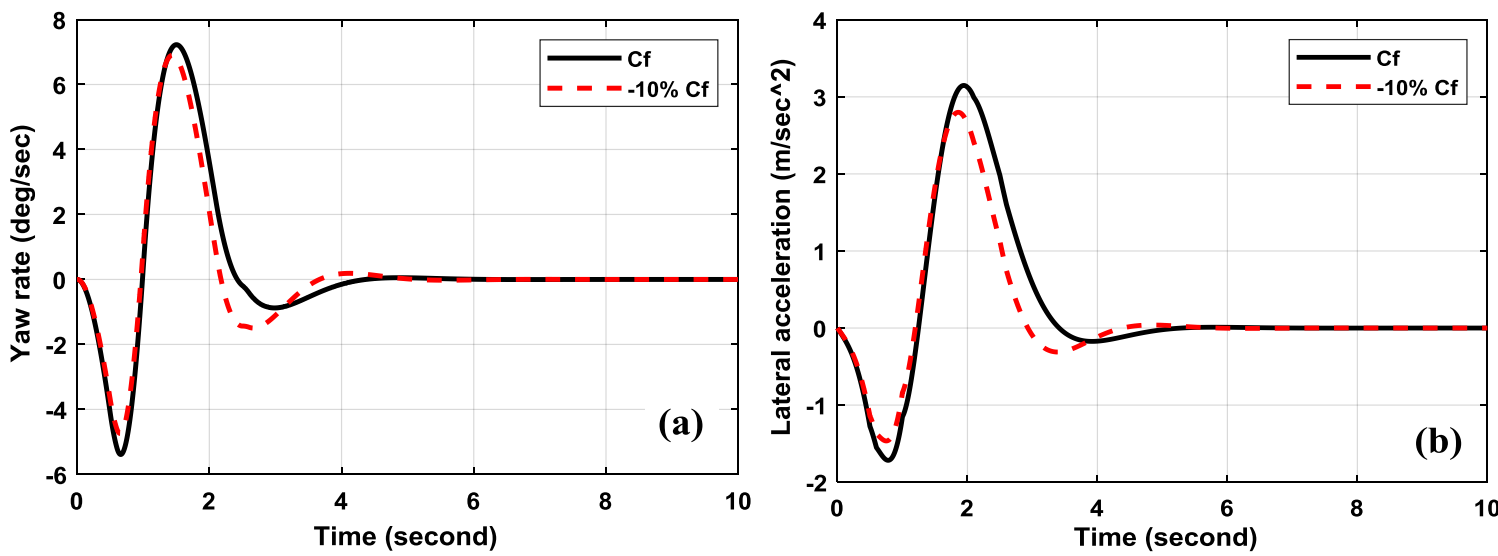

Fig.7.Handling performance at -10 front cornering stiffness variation, (a) yaw rate, (b) lateral acceleration.
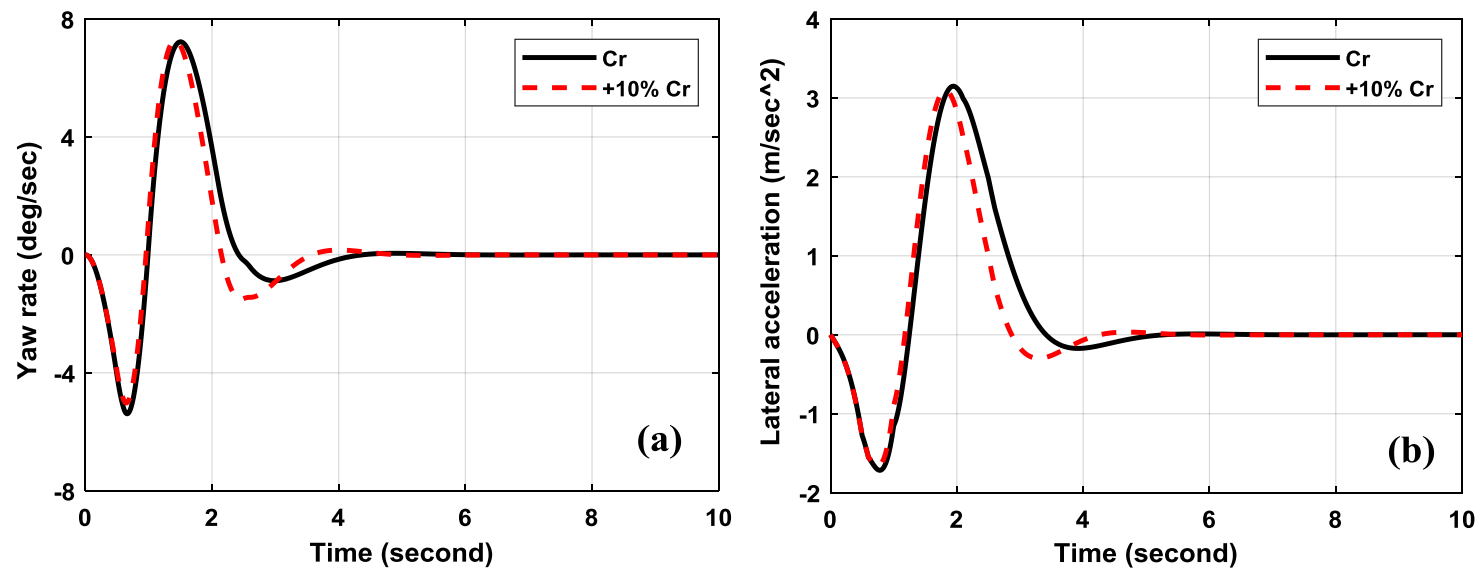

Fig.8.Handling performance at $+10 \%$ rear cornering stiffness variation, (a) yaw rate, (b) lateral acceleration. 

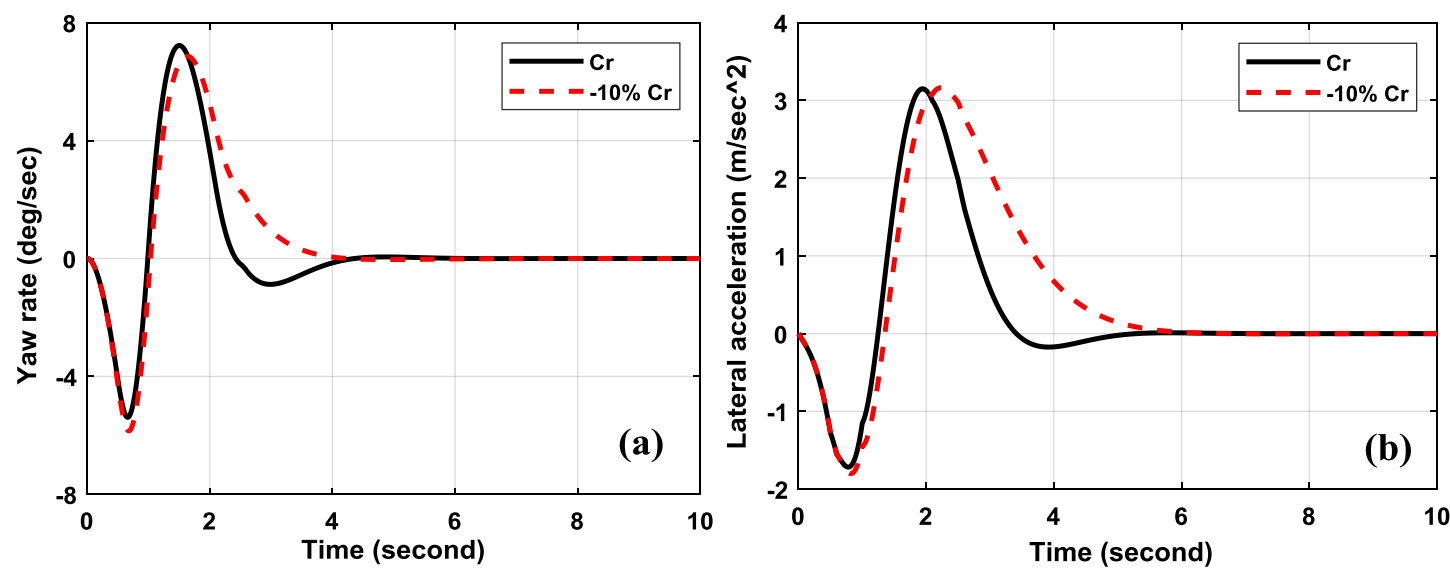

Fig. 9. Handling performance at $-10 \%$ rear cornering stiffness variation, (a) yaw rate, (b) lateral acceleration.

Figures 10a, 10b, 11a, 11b, 12a, and 12 bpresent the influence of vehicle mass and vehicle speed respectively on yaw rate and lateral acceleration. While Figs. 13 and 14 investigate the position of the vehicle
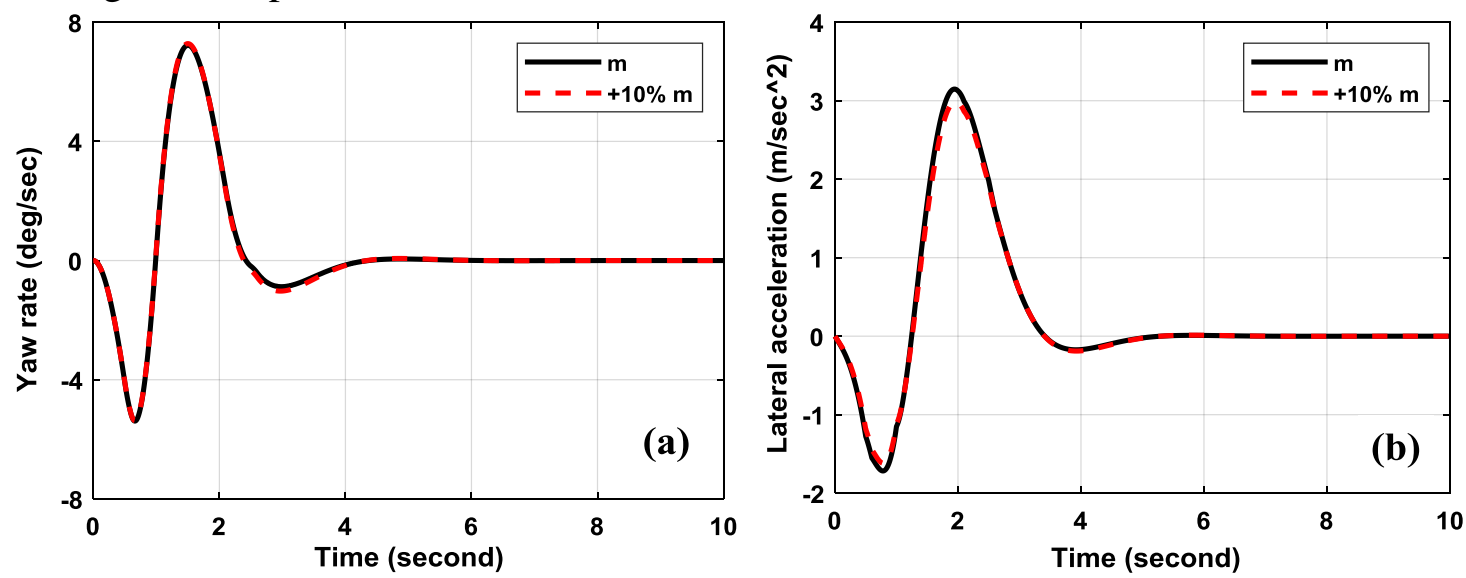

Fig. 10. Handling performance at $+10 \%$ vehicle mass variation, (a) yaw rate, (b) lateral acceleration.
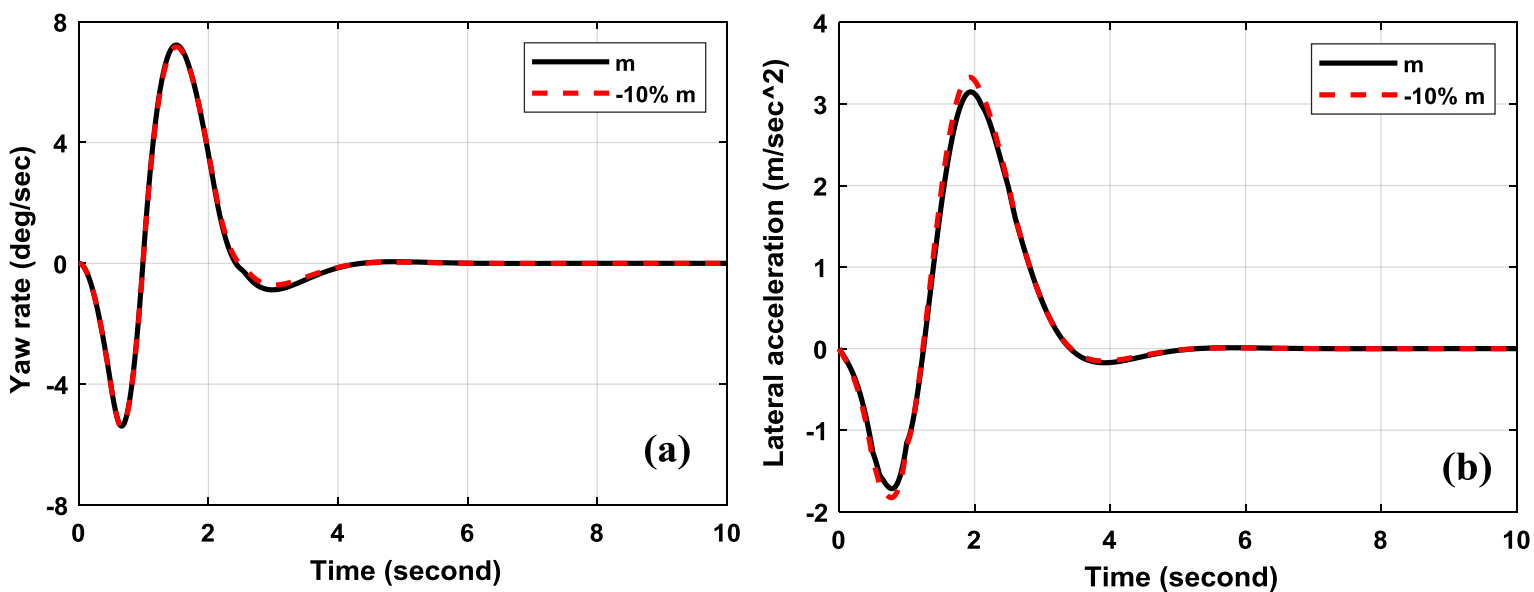

Fig.11.Handling performance at $-10 \%$ vehicle mass variation, (a) yaw rate, (b) lateral acceleration. 

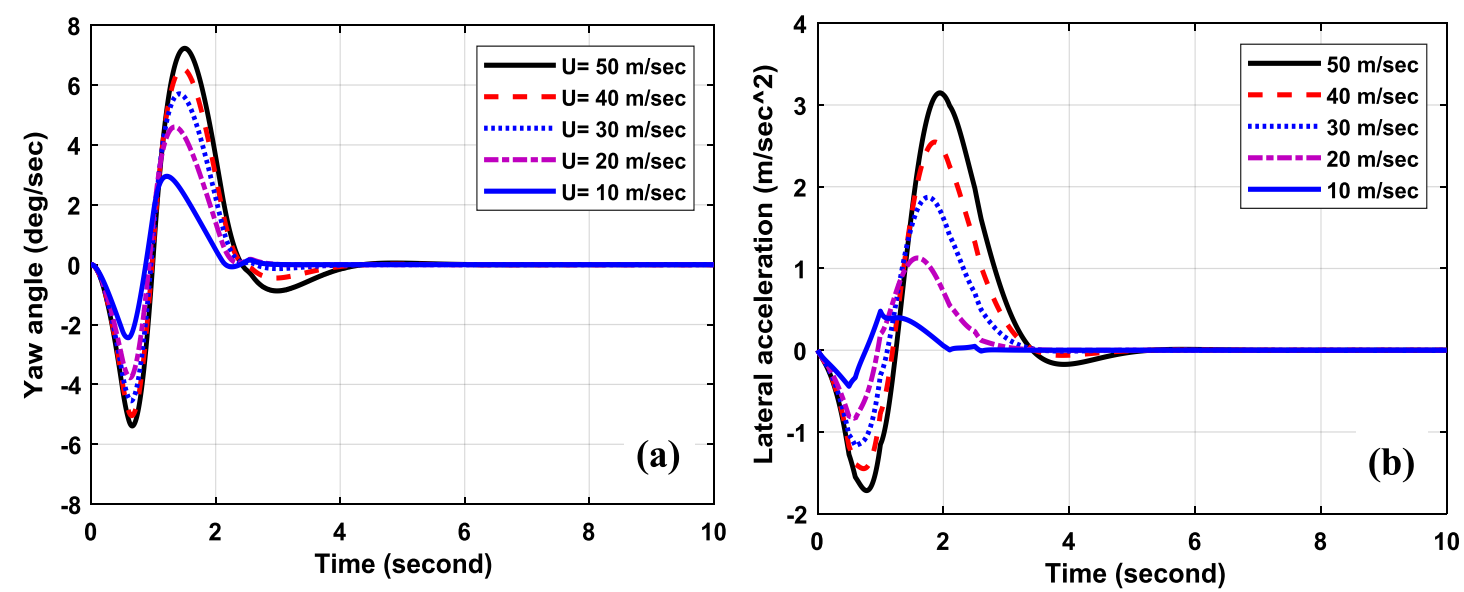

Fig.12.Handling performance at varies vehicle speeds, (a) yaw rate, (b) lateral acceleration.
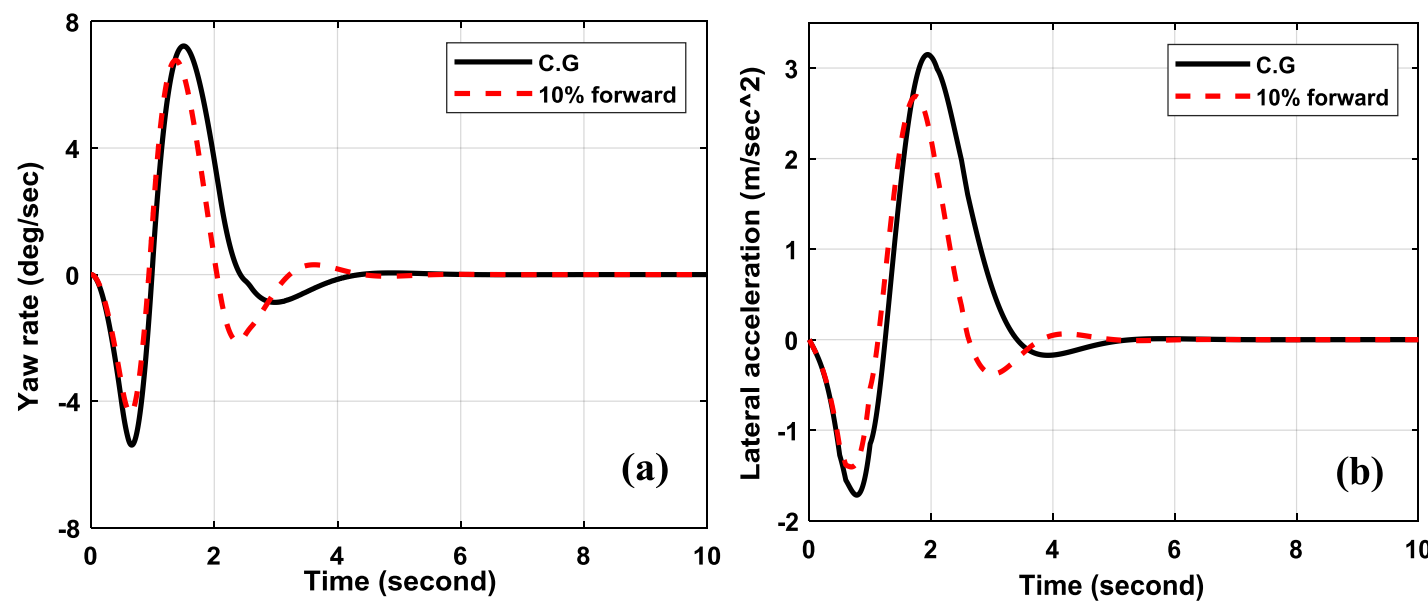

Fig.13.Handling performance at 10\%C.G forward shifting, (a) yaw rate, (b) lateral acceleration.
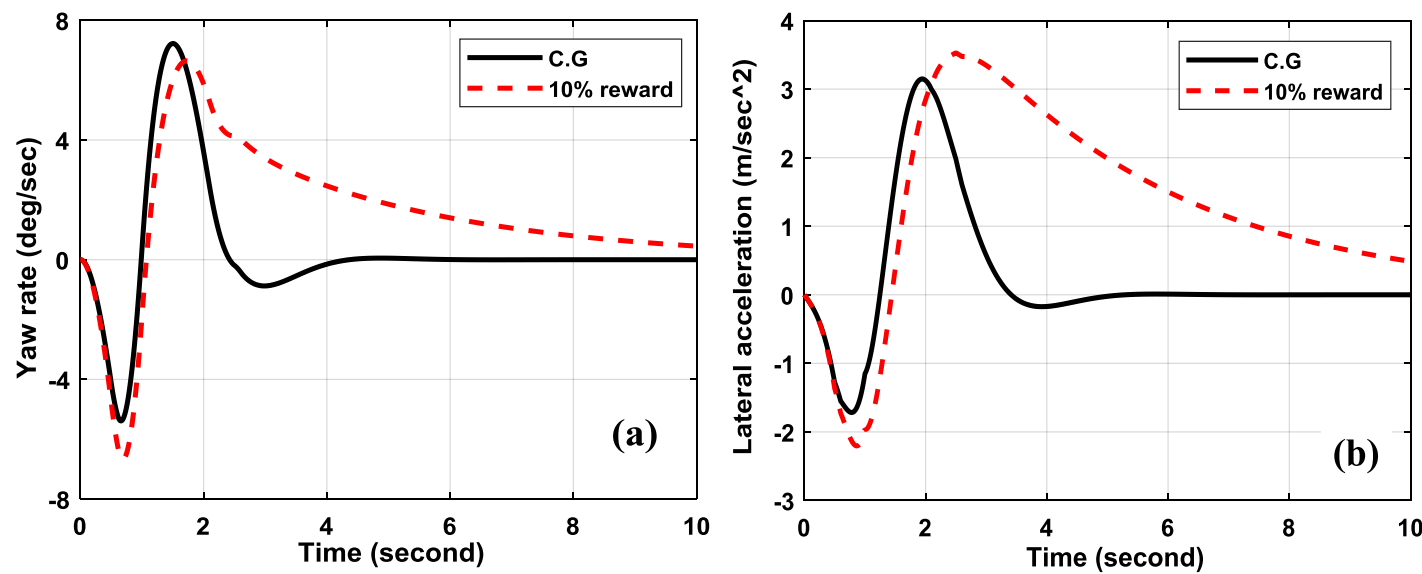

Fig. 14.Handling performance at 10\% C.G reward shifting, (a) yaw rate, (b) lateral acceleration.

Table 3 presented the RMS value of vehicle handling indices under typical steering input during vehicle maneuvering. These RMS investigate the values of vehicle output for vehicle parameter influence. Table 4 presented the percentage of change in vehicle output forces; this change investigates the effect of vehicle parameters on vehicle handling output during its maneuvers. The change in vehicle handling output presneted the improvement and the negative effect of this influence in vehicle parameters for typical steering input. Table 5 presented the change in under steering gradient stability for the vehicle model under this maneuver. This investigates the effect of vehicle parameters on steering type, steering gradient change. 
Journal of Advanced Engineering Trends (JAET), Vol. 39, No. 1. January 2020

Table 3. RMS vehicle handling value due to the influence in vehicle parameter.

\begin{tabular}{|c|c|c|c|c|c|}
\hline \multirow{2}{*}{ Vehicle parameter } & \multirow{2}{*}{$\begin{array}{c}\text { Percentage of } \\
\text { change }\end{array}$} & \multicolumn{4}{|c|}{ RMS } \\
\cline { 3 - 6 } & $+10 \%$ & Yaw rate & Yaw angle & Lateral acc. & Lateral deviation \\
\hline $\begin{array}{c}\text { Front wheel Cornering } \\
\text { stiffness }\end{array}$ & $-10 \%$ & 1.924 & 1.732 & 0.8129 & 0.8001 \\
\cline { 2 - 5 } & $+10 \%$ & 2.024 & 1.884 & 0.9038 & 0.7909 \\
\hline $\begin{array}{c}\text { Rear wheel cornering } \\
\text { stiffness }\end{array}$ & $-10 \%$ & 2.27 & 4.359 & 1.201 & 0.7894 \\
\cline { 2 - 6 } & $+10 \%$ & 2.145 & 2.42 & 0.9517 & 1.236 \\
\hline \multirow{2}{*}{\begin{tabular}{c} 
Vehicle mass \\
\cline { 2 - 5 } C.G position
\end{tabular}} & $-10 \%$ & 2.123 & 2.629 & 1.053 & 1.114 \\
\cline { 2 - 5 } & Forward $10 \%$ & 1.83 & 1.46 & 0.7595 & 0.5931 \\
\hline
\end{tabular}

Table 4. Percentage of improvement in vehicle handling with vehicle parameters influence.

\begin{tabular}{|c|c|c|c|c|c|}
\hline \multirow{2}{*}{ Vehicle parameter } & \multirow{2}{*}{$\begin{array}{l}\text { Percentage of } \\
\text { change }\end{array}$} & \multicolumn{4}{|c|}{ Percentage of change $\%$} \\
\hline & & Yaw rate & Yaw angle & Lateral acc. & Lateral deviation \\
\hline \multirow{2}{*}{$\begin{array}{c}\text { Front wheel Cornering } \\
\text { stiffness }\end{array}$} & $+10 \%$ & +11.4 & +65 & +26.7 & -32 \\
\hline & $-10 \%$ & -10 & -31.2 & -19 & -33 \\
\hline \multirow{2}{*}{$\begin{array}{c}\text { Rear wheel cornering } \\
\text { stiffness }\end{array}$} & $+10 \%$ & -5 & -25.2 & -10 & -54 \\
\hline & $-10 \%$ & +6.5 & +73 & +20 & +96 \\
\hline \multirow{2}{*}{ Vehicle mass } & $+10 \%$ & +0.6 & -4 & -5 & +5 \\
\hline & $-10 \%$ & -0.5 & +4.4 & +5.3 & -5.4 \\
\hline \multirow{2}{*}{ C.G position } & Forward $10 \%$ & -14.5 & -42 & -24 & -50 \\
\hline & Reward $10 \%$ & +35 & +313 & +93 & +357 \\
\hline
\end{tabular}

Figures $15 \mathrm{a}$ and $15 \mathrm{~b}$ investigate vehicle tire cornering stiffness influence on vehicle handling output during its maneuver with

typical steering input. The figures were between the percentage of vehicle front tire and rear cornering stiffness and RMS of vehicle handling output.

Table 5. under steer gradient with influence vehicle parameter.

\begin{tabular}{|c|c|c|}
\hline Vehicle parameter & Percentage of change & Under steering gradient (deg/g) \\
\hline \multirow{2}{*}{ Front wheel Cornering stiffness } & $+10 \%$ & 0.195 \\
\cline { 2 - 3 } & $-10 \%$ & 1.79 \\
\hline \multirow{2}{*}{ Rear wheel cornering stiffness } & $+10 \%$ & 1.548 \\
\cline { 2 - 3 } & $-10 \%$ & 0.137 \\
\hline \multirow{2}{*}{ Vehicle mass } & $+10 \%$ & 1 \\
\cline { 2 - 3 } & $-10 \%$ & 0.822 \\
\hline \multirow{2}{*}{ C.G position } & Forward 10\% & 2.3 \\
\cline { 2 - 3 } & Reward $10 \%$ & -0.472 \\
\hline
\end{tabular}
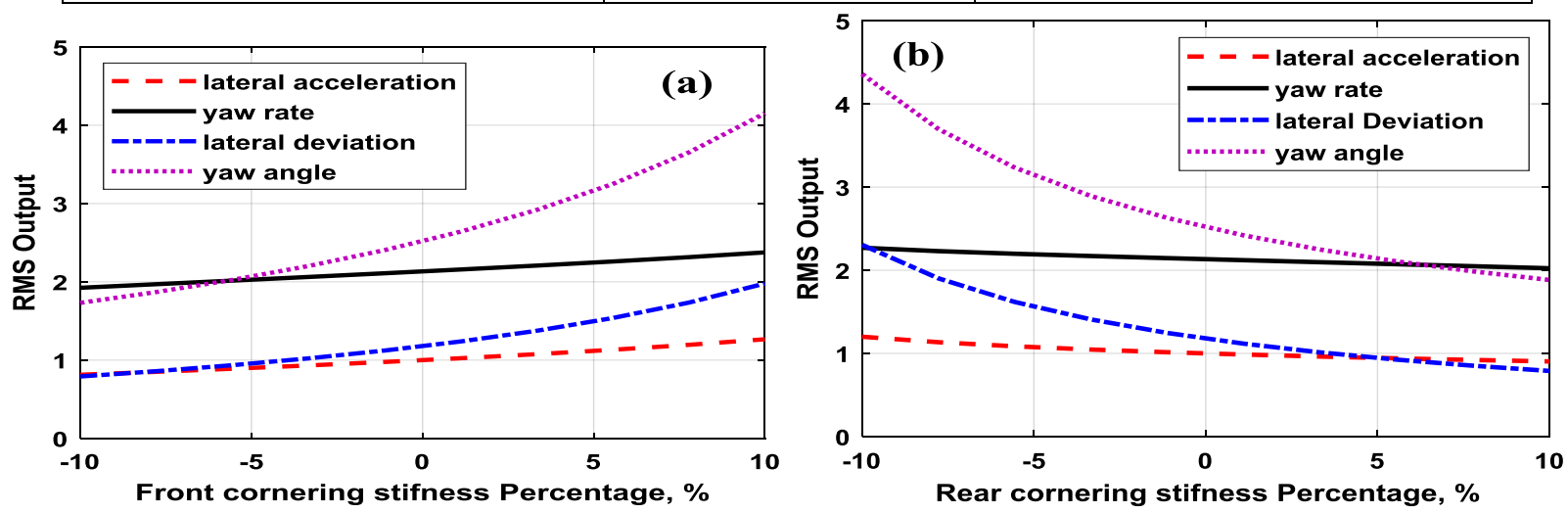

Fig. 15.Effect of cornering stiffness on vehicle handling during its maneuver at typical wheel steer angle at vehicle speed $50 \mathrm{~m} / \mathrm{s}$. 
Figure 16 presented the effect of vehicle mass variation and vehicle speed on the vehicle handling indices terms of RMS during its maneuvers. The output of vehicle performance during influence in vehicle mass was at typical wheel steer angle at vehicle speed $50 \mathrm{~m} / \mathrm{s}$; then the varies vehicle

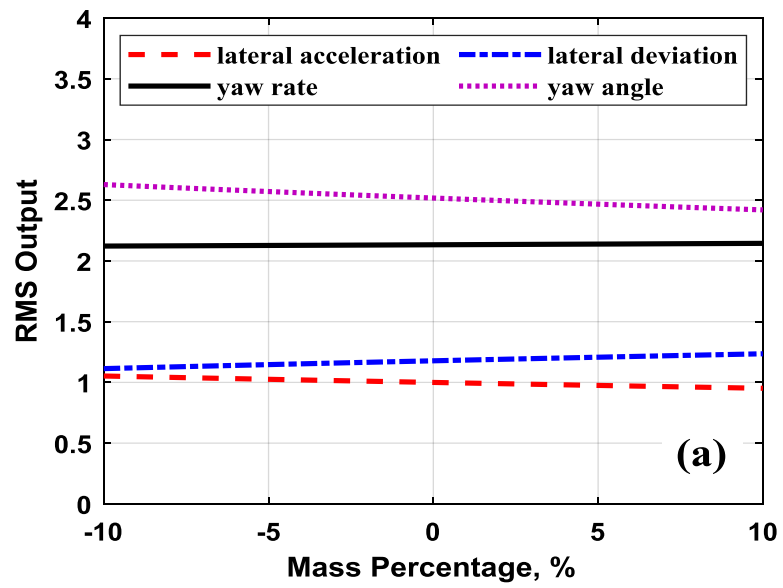

speed effect on vehicle dynamic stability was also presented at constant vehicle mass. Figure 17 presented the effect of the vehicle center of gravity effect on vehicle handling output during its maneuver at typical wheel steer angle input and at vehicle speed 50 $\mathrm{m} / \mathrm{s}$.

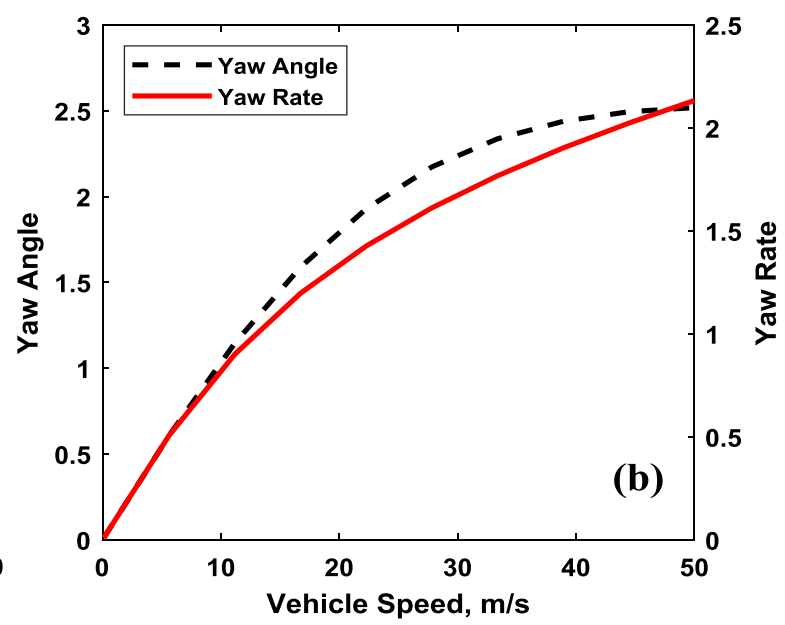

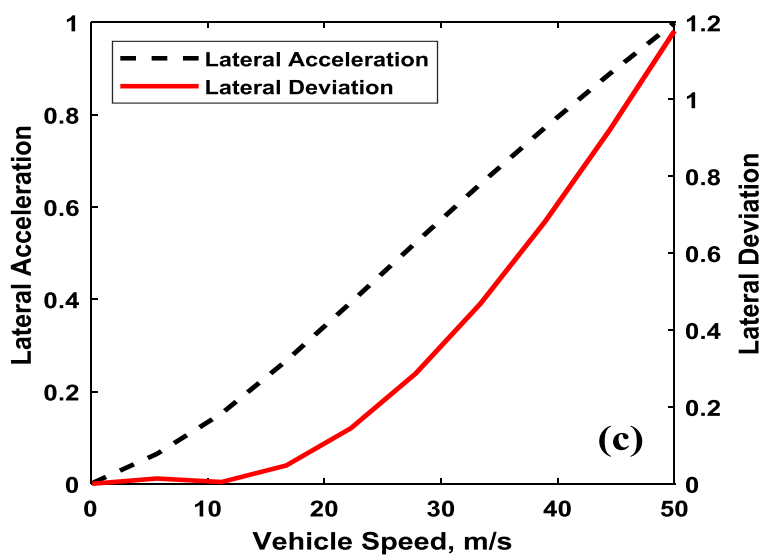

Fig. 16. Vehicle handling at typical wheel steer angle, (a) effect of vehicle mass at vehicle speed $50 \mathrm{~m} / \mathrm{s}$, (b) RMS of yaw angle and yaw rate with varies vehicle speeds, (c) RMS of lateral deviation and lateral acceleration and varies vehicle speeds.
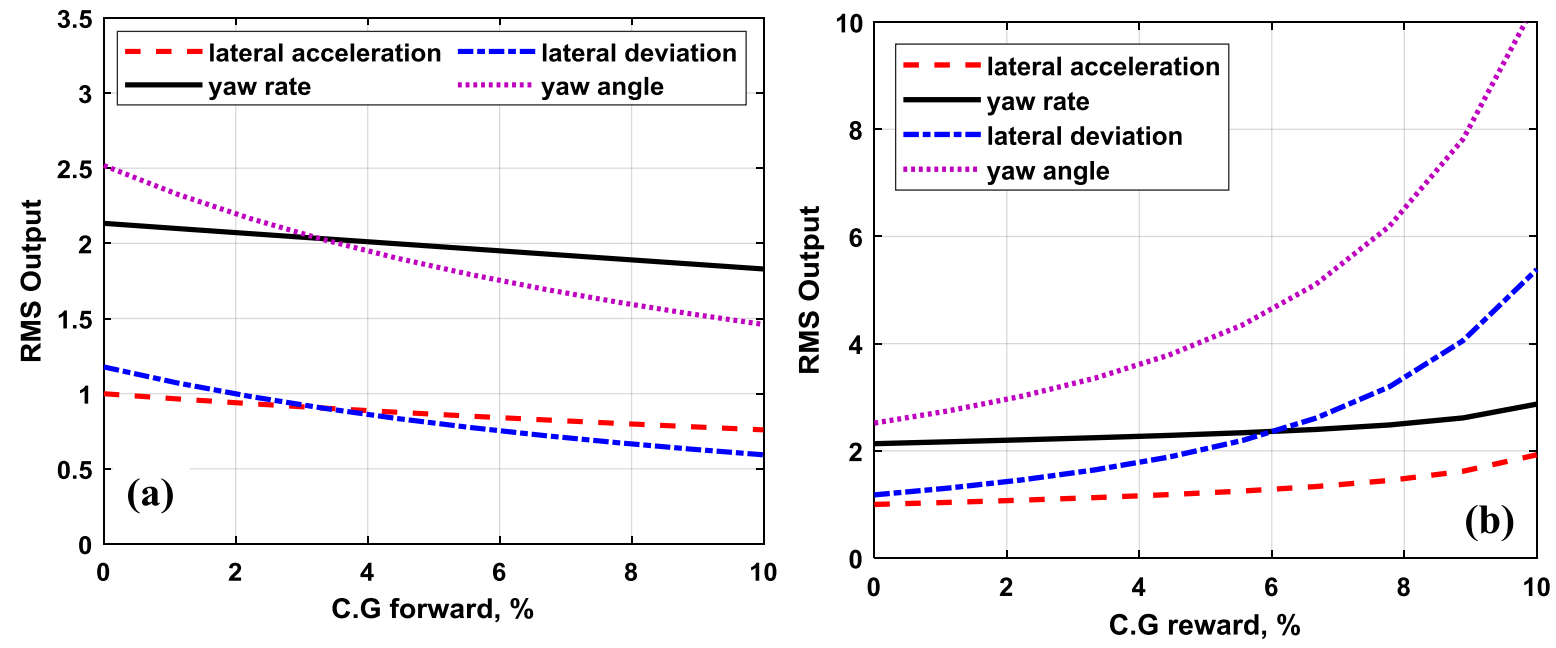

Fig.17.Effect of vehicle C.G position on vehicle handling at typical wheel steer angle and speed of $50 \mathrm{~m} / \mathrm{s}$, (a) change in position center of gravity forward, (b) change in the center of gravity reward. 


\section{CONCLUSION}

In this paper, complete parametrical and conflict analyses including the geometrical and vehicle design parameters were conducted. During the simulations, a 2DOFs bicycle-vehicle model was implemented and verified using the MATLAB/Simulink and thereafter two steering modes (step input and typical steer angle) were used to examine the sensitivity of vehicular stability and handling performances. In this manner, both the yaw rate and vehicle lateral acceleration were mainly considered as the vehicle stability indices.

Given the simulation results, significant influences on the vehicular stability and handling indices were observed when the position of thevehicle center of gravity was $10 \%$ shifted either to the forward and reward. This is related to the change in vehicle form the under steering zone to the over steering zone. On the other hand, the vehicle mass presented a slight effect on vehicle stability and handling which can be neglected. Finally, the other remaining parameters presented fluctuated vehicle dynamic stability with lower impact on vehicle under steering gradient.

\section{REFERENCES}

[1] MATLAB. The MathWorks. Inc, United States, patents. 2005.

[2] Ko, Y. and C. Song, Vehicle modeling with nonlinear tires for vehicle stability analysis. International Journal of Automotive Technology, 2010. 11(3): p. 339-344.

[3] Khan, M.M., A.U. Awan, and M. Liaquat,Improving Vehicle Handling and
Stability under Uncertainties using Probabilistic Approach. IFAC-PapersOnLine, 2015. 48(25): p. 242-247.

[4] Subramaniyam, K.V., C.N. Kumar, and S.C. Subramanian, Analysis of Handling Performance of Hybrid Electric Vehicles. IFAC-PapersOnLine, 2018. 51(1): p. 190-195.

[5] Kirli, A. and M.S. Arslan, Optimization of parameters in the hysteresis-based steering feel model for steer-by-wire systems. IFACPapersOnLine, 2016. 49(3): p. 129-134.

[6] Tavoosi, V., R. Kazemi, and S. Hosseini, Vehicle handling improvement with steer-bywire system using hardware in the loop method. Journal of applied research and technology, 2014. 12(4): p. 769-781.

[7] Lee, S., K. Nakano, and M. Ohori, Identification of yaw moment of inertia of a truck during travelling. IFAC Proceedings Volumes, 2013. 46(21): p. 768-772.

[8] De Bruyne, S., et al. Online estimation of vehicle inertial parameters for improving chassis control systems. in IFAC World Congress. 2011.

[9] Mazumder, H., et al., Performance analysis of EV for different mass distributions to ensure safe handling. Energy Procedia, 2012. 14: p. 949-954.

[10] Lin, C., et al., Estimation of Center of Gravity Position for Distributed Driving Electric Vehicles Based on Combined Hळ-EKF Method. Energy Procedia, 2016. 88: p. 970-977.

[11] Wesemeier, D. and R. Isermann, Identification of vehicle parameters using stationary driving maneuvers. Control Engineering Practice, 2009. 17(12): p. 1426-1431.

[12] Crolla, D., G. Firth, and D. Horton, An introduction to vehicle dynamics. 1992: University of Leeds, Department of Mechanical Engineering.

[13] Ranganathan, R. and A. Aia, Development of heavy vehicle dynamic stability analysis model using MATLAB/SIMULINK. 1995, SAE Technical Paper. 


\section{دراسة تاثير المعاملات التصميمية على اداء ثبات السبارة}

مينا مجدى (براهيم ، خالد على عبد الجواد ، محى الدين مصطفى سالم ، محمد على حسن مراد

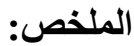

في هذه البحث ، يقترح نموذج نصف سيارهه طولى لدراسة ثبات السيارة الديناميكي في اكثر من مناورة للمركبة. تم نطوير المحاكاة باستخدام برنامج تطبيق MATLAB / Simulink للتنبؤ بالاستقرار الديناميكي للمركبة في إطار مناورات مختلفة. للتحقق من ثبات السيارة ، يتم اختيار زاوية عجلة القيادة لتكون مدخلات النموذج الأساسي لإجراءات التحليل. ينم التحقق من صحة النموذج المطوّر عبر إدخال زاوية توجيه للسيارة علاوة على ذلك ، تم ادخال زاوية عجلة نوجيه جديدة لفحص مخرجات السيارة التي ينم التتبؤ بها على الطريق السريع داخل المناورة. يتم اعتماد المخرجات الديناميكية للمركبة ، وهي زاوية ال yaw و لجميع المناورات التي تم فحصها. لقد وجد أن معاملات تصميم السيارة منل تغيير وضع مركز lateral acceleration ثقل السيارة (CG) ، وكتلة السيارة ، وصلابة إطار الإطارات وسرعة السيارة لها نأثثر كبير على ثبات السيارة الديناميكي. التغيير في مركز السيارة من موقف الجاذبية هو أكثر المعلمة له نأثير في ديناميات استقرار السيارة. 